\title{
The continuum of dental
}

\section{education and its environment}

$\mathrm{T}$ The concept of the continuum of dental education has undoubtedly been strengthened by the GDC's educational initiatives over the past few years. In the revised First Five Years document, published in August 2002, the emphasis has shifted from recommendations in the undergraduate curriculum to learning outcomes, which encompass the wider needs of the dental professional. This includes behavioural sciences, communication skills, ethical and cultural awareness and team-working. The main message is that undergraduate education is the start of a continuum of lifelong learning, and courses will need to ensure that these professional skills, personal development and self assessment through reflection are all taught (or their learning facilitated) in the new curriculum.

Lifelong learning is no longer an option for a professional, but rather an obligation, and the onus for continuing professional development will rest on the individual practitioner. It is implied that dentists should, therefore, recognise their own developmental needs and in which areas they should be updating or improving their knowledge or skill for the benefit of their patients. With the statutory registration of all members of the dental team also imminent, dental nurses, dental technicians and oral maxillofacial prosthetists will join those members of the dental team, the hygienists and therapists, who are already enrolled with the GDC. The team-working aspect of dental training for the graduate will need to be strengthened and continued throughout the vocational and general professional training courses.

In contemporary dental practice, the patient is a consumer who is well educated and seeks information about treatments and available alternatives, and patients in general are tending to become more litigation conscious. It is important that future practitioners will not only be able to deliver the highest standards of oral health care, but also to deliver a service designed to meet the changing oral health needs as well as the demands of the 'customer' in the dental practice setting. As the primary care service is strengthened by GDPs with special interests and with specialist dental practice emerging in high street locations, the emphasis on treatment in the secondary care sector will be diminished.

What are the implications of all of the above on the provision of dental education?

The learning environment provided for the dental student or trainee takes on a greater significance as we strive to achieve the objectives laid down by the GDC. Is the dental school setting therefore the best environment for the training of the future dental professional? In order to inculcate the values with respect to professionalism, communication, ethics etc. much can be achieved by paying attention to the environment that the students are exposed to i.e. optimising the 'hidden curriculum'. Providing the most appropriate learning environment will mean exposure to dentistry not only within the dental hospitals but also through outreach schemes, with the challenge being to ensure that the latter will still be sufficiently controlled to enable achievement of the educational and clinical objectives.

In the future, with the acknowledgement that dental schools are an expensive way of delivering dental education and the improvement in computer literacy and IT facilities such as internet, digital imaging, electronic patient records, educational strategies will incorporate computer assisted learning and problem based learning innovations. Thus, collaborative working relationships in dental education might be revolutionised. Dental schools would continue to play a key role as centres of clinical, educational and research excellence with economy of scale being an advantage. However academic staff would be able to redirect some of their time into directing education, reinforcing the scientific basis of dentistry and supervising research, with a reduction in their role as treatment providers and clinical supervisors on a day to day basis.

The GDC document summarises, in its appendix, the blueprint for this by outlining what the dentist is able to do, how the dentist approaches their practice and the qualities of the dental practitioner as a professional. If we can provide the appropriate clinical and educational environment the undergraduate dental curriculum will provide a seamless transition into all aspects of postgraduate dentistry creating a true and effective continuum of dental education.

Peter Mossey, BDJ Adviser on Dental Education
'Lifelong

learning is no

longer an

option for a

professional,

but rather an

obligation,

and the onus

for

continuing

professional

development

will rest on

the individual

practitioner."

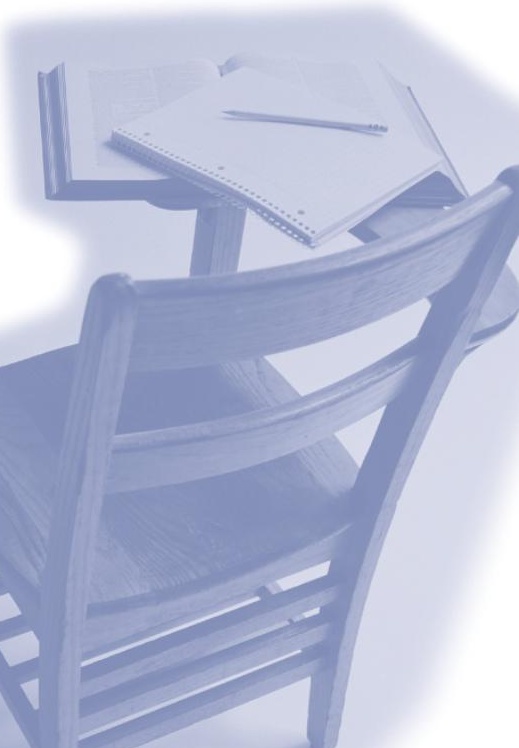

